\title{
The Application of Seismic Facies Recognition Technology in Sedimentary Facies Research of Cambrian at East of Tarim Basin
}

\author{
Liu Yang \\ Exploration and Development Research Institute, Daqing Oilfield Company Limited
}

\begin{abstract}
The exploration and geology research level is lower at East Tarim basin and the studying of carbonate reservoir at deeper basin is also inadequate in special. Dolomite of Cambrian is the prospect area, there has good condition to form high quality stratum which will be got breakthrough on exploration of oil and gas. the study aim at the uplift belt of East Tarim basin (low uplift of Gucheng- uplift of East Tarim basin - uplift of Lop Nur), optimized 267 2D seismic survey line $24670 \mathrm{~km}$ in total which cover the whole area with no less than $16 \times 16 \mathrm{~km}$ grid density, basic on the fine structure interpretation, make full use of the area for drilling, well logging and core data, combined with peripheral outcrop zone and the predecessors' research result to study the paleogeography and controlling factors of the carbonate stratum of Cambrian in East Tarim basin by means of seismic facies studying system, the result provide important reference for oil and gas exploration in this area.
\end{abstract}

Keywords-seismic facies; east of tarim basin; cambrian; sedimentary facies.

\section{INTRODUCTION}

Seismic data application is essential in the study of sedimentary facies, well logs and plane facies forecast. By the way, the studying is restrained by the quality of the seismic data. Because the exploration time span is big at East Tarim basin and the quality of seismic data is unbalanced, so it is difficult to use computer software to realize the seismic facies analysis. The only effective way to realize the research of sedimentary facies in the area is to identify the section by technicians firstly and then to derive the method of plane distribution.

The mainly exploration in East Tarim basin is 2D seismic line and there are two blocks of 3D. 13 prospecting wells drilled in the Cambrian strata. Application of synthetic seismogram and VSP data calibrate the drilling geological stratification line on the seismic profile finely, and track the seismic horizon interpretation in trisection Cambrian stratum. Which is revealing that the Cambrian of East Tarim basin area contains two platforms, namely on the west side of the Gucheng platform and on the east side of the Luoxi platform.

\section{SEISMIC FACIES RECOGNITION}

In order to distinguish between platform facies, platform margin facies and basin facies, The different seismic reflection structures are identified by the means of interpretation of the seismic section base on the analysis of drilling, logging data. 5 types of seismic facies were identified in Cambrian of East Tarim basin area (Figure 1), and seismic facies horizontal distribution diagram were drew (Figure 2). There has obvious different seismic response characteristics From platform to platform marginal zone and slope zone and the basin area. It has a plate shape medium to high amplitude in platform, in parallel to sub-parallel, better continuity, some weak amplitude discontinuous mixed and disorderly - wave - weak progradation reflection (Figure 1 a). Platform marginal zone Platform developed reef (hill) and beach complex which has hummocky shape, beach body clutter reflection or blank reflection characteristics (Figure 1b). platform margin slope facies has the wedge shape progradation unit to deep sea direction, medium to high amplitude and with oblique progradation reflection structure and imbricate progradation structure (Figure 1c);

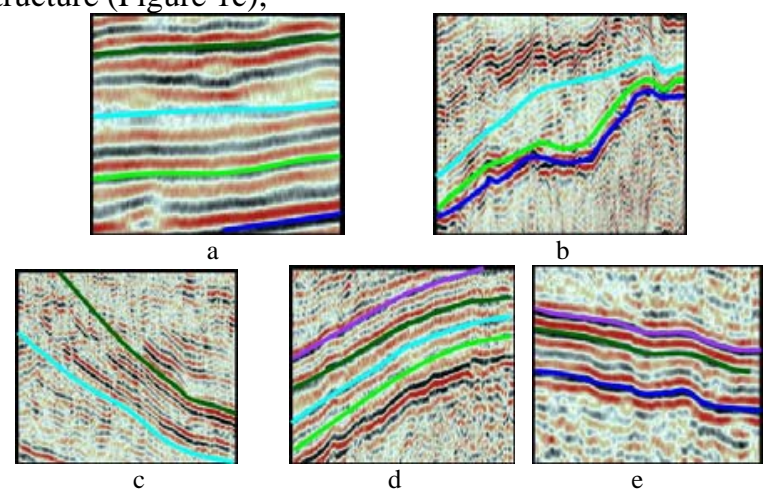

Figure 1.5 types of seismic facies in Cambrian of East Tarim basin area

Basin area includes continental shelf and deep sea basin, is characterized by the parallel appearance, strong amplitude, and continuity (Figure 1d). Deep sea basin is a typical sheet distribution characteristics, with medium to high amplitude, better continuity, stable parallel, all these reflects a kind of low energy environment of mudstone and shale sedimentary (Figure 1e). It is difficult to distinguish between them only rely on seismic facies, so it is depend on the formation thickness threshold value to distinguish. On the seismic section, therefore, the larger complex (hill) of reef beach and rapid sedimentary thickness thinning to basin region as evidence to judge the margin of the platform. the platform margin mounded shape, the beach body clutter reflection or blank reflection and medium frequency, medium-high amplitude, parallel to the parallel, better 
continuity of seismic facies in platform is distinguished as the boundary of inner and margin of platform.

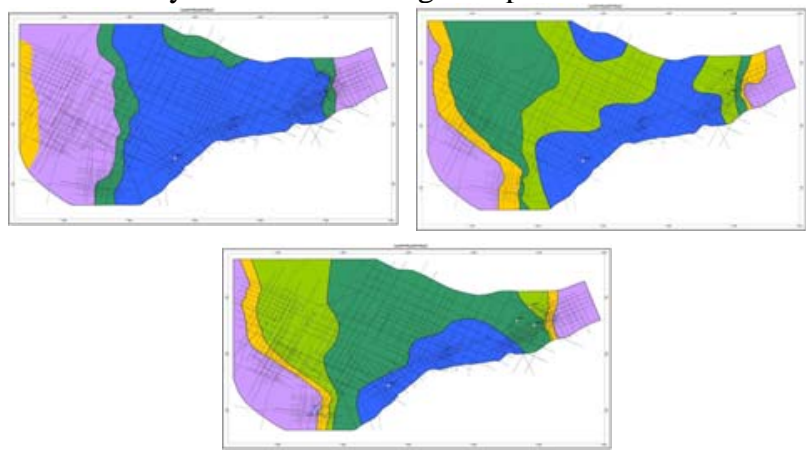

Figure 2. Early (L), middle(C) and late (R) Cambrian seismic facies map

\section{GEOMORPHOLOGY}

Cambrian strata is intact in East Tarim basin region, there has no big unconformity interface cause of strata denudation or deletion, the ancient landscape of sedimentary period can be restored basically through the formation thickness. Carbonate sedimentary thickness of Cambrian is big in central Tarim basin and west of East Tarim basin, There are two ruptures relative to the basin area. the characteristics of sedimentary thickness increased obviously in the west of the Luoxi region is the landform conditions to form the ancient carbonate platform. the topographical features reveals From time thickness since the early Cambrian, the middle Cambrian to late Cambrian (Figure 3), the rupture of two stage uplift geomorphic features is still exist in central Tarim basin and Gucheng. The rupture of the early Cambrian is not obvious in Luoxi platform, the middle Cambrian and late Cambrian also has the characteristics of the rupture of platform margin. That is the palaeogeomorphology is high and carbonate sedimentary thickness is big on east and west sides, the sedimentary thickness is thin and the palaeogeomorphology is low in central area. high landscape area is to arc distribute in north and south and to form two ruptures of platform in Gucheng areas and Lop Nur area respectively.
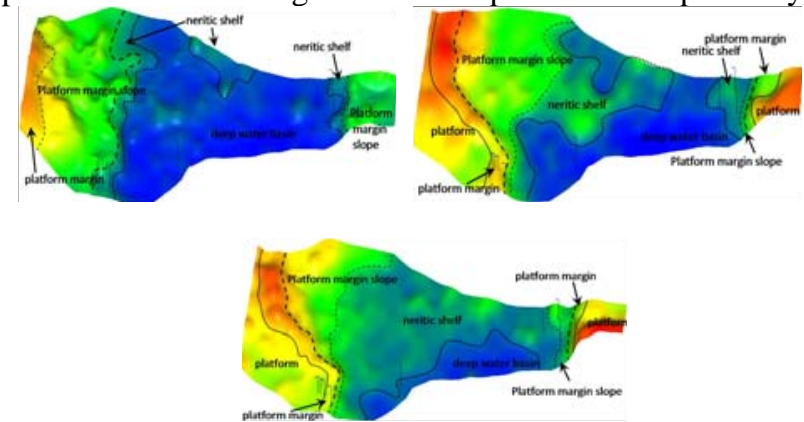

Figure 3. Early (L), Middle(C) and Late(R) Cambrian paleogeomorphology 3D map

There are exist Guccheng platform and Luoxi platform in east Tarim basin region. Between the platform and basin areas where it is developping of different shape and size of ruptures. The geomorphology features shown as a series of thickness can be seen that the rupture of Lundong-Gucheng is "S" shape in north and south direction, wide in north and narrow in south. East of rupture is deep-sea deposition under-compensation region of Manjiaer depression. west of rupture is central Tarim basin carbonate platform facies sedimentation. Which is controlled by the early tectonic activities, Slope of Luoxi rupture is big. sea-level change on vertical has no big impaction on rupture lateral migration. the Cambrian main performance characteristics of multiple phase ruptures stack on vertical.

Seismic section of Gucheng, Mannan, Caonan reveals the Cambrian in carbonate platform margin has different forms in different locations. Caonan in the north has the platform margin shape in middle and up Cambrian. The top of middle Cambrian is shown truncation characteristics and slope is lower at the edge. Platform margin shape is steep and prograde superimposed style in up Cambrian and migration to the basin, as the edge truncation type. Platform margin is not obvious in Mannan central of East of Tarim basin, with little change of the thickness, is weak edge type. Gucheng southern of East of Tarim basin has obvious edge platform margin shape. It is large-scale progradation structure which developing within the margin belt.

\section{SEDIMENTARY FACIES PREDICTION}

In early Cambrian, East Tarim basin located on the verge of craton depression intense extensional environment, large-scale seawater intrusion and formed in deep depression trough basin around Manjiaer. The basin area is larger in early-middle Cambrian, the sedimentary center is around the MD1 well. TD1 well, TD2 well, ML1 well and YD2 well show a trench mud limestone in the sedimentary basin facies mudstone in lower Cambrian. In western tarim located the western tarim basin Intracratonic depression, mainly for a set of carbonate deposition platform facies, TC1 drilled a limited tidal-flat facies dolostone reservoirs in lower Cambrian. The Gucheng area located in carbonate rocks gently dipping slope, in the north, along with the river of peacock is deep-sea basin facies sedimentary (Figure 4). Early Cambrian is mainly deep-water basin facies, the sedimentary center is around MD1 well, mainly for the black shale and siliceous rock deposits. 4 small pelvic floor fan is developed in basin and distributed within Yingjisu depression and east of Manjiaer depression (Shao Longyi, 2008). Platform margin slope facies with a north-south extent belt is developed on both sides of west and east in the basin. facies zone is narrow western Gucheng-Lunnan slope facies, on average, about $28 \mathrm{~km}$ wide. Tarim basin area east of Lop Nur were a platform facies dolomite and micrite in lower Cambrian that suggests Lop Nur were developed carbonate platform in eastern region in early Cambrian, Luoxi slope is about $15 \mathrm{~km}$, gradient is relatively gentle slope. The side face the continental is connected to the open land which has half a restricted platform in southwest. In two carbonate platform facies zone and with trough basin facies zone should exist transition area between basin and platform, though none prospect well drill the transitional facies belt, but on the seismic profile, there 
have reflection characteristics of the platform marginal facies in Lundong-Gucheng and Luoxi region.

From the middle Cambrian, the study area started large-scale regression, deep sea basin facies atrophy obvious, west Tarim basin are mainly restricted platform and open platform facies. A set of restricted platform facies dolomite clip lagoon facies cream dolomite deposited TC1 well in lower Cambrian (Figure 5). Manjiaer depression is still the deposition center in this period. TD1 well and TD2 well in the southern margin the tarim basin are shallow sea shelf limestone, marl deposition. ML1 and YD No. 2 well platform margin slope facies mudstone and muddy dolomite and dolomitic mudstone deposit, half restricted platform evolutes to restricted platform for the sea retreat reason. Each facies migrate estward successivly. five platform margin reef sedimentary body are built in Gucheng slope facies zone, which are low-rising mounds on seismic section, with low angle imbricated structure. the reef bodys along the slope belt in en echelon arrangement at plane. lithology is mainly for coagulation stone plaster hill which is an identification marks of early platform edge facies. Seismic profiles show that Lundong-Gucheng platform margin due to sea level falling, migrate eastward of about $20 \mathrm{~km}$. Luoxi rupture is characterized by vertical accretion characteristics, shelf slope and shallow water shelf facies are developed extensively between the platform and deep water basin.

plane distribution of sedimentary facies characteristics is similar broadly in middle Cambrian and late Cambrian, with very good inheritance, the basin range become smaller continuously, platform edge facies and reef complex include laminated stromatolite mud mound and algal reef migrate and growth to basin continually. (Figure 6). Reef complex has buildup characteristic obvious, which shows as mound shape in the seismic section, large-scale high angle progradation configuration can be seen at inside. shoal facies developed at platform edge and reef complex in Gucheng area. In peacock river area developed nodular limestone and shale interbed which belongs to the cockpit transition shale basins. TD1 well and TD2 well has neritic shelf facies development, lithology include mud limestone, shale and marl mainly. YD2 well, ML1 well area developed platform edge collapse deposit and carbonate turbidite deposit, which belongs to the platform front slope sedimentary, lithology include mud dolomite and dolomitic mudstone and mudstone and somewhere has laminated development. LX1 well is gray residual algae arene dolomite and arene dolostone mainly in up-Cambrian, dolomitization sand dust particles is visible obvious by microscope. That is a typical platform edge shallow water beach sedimentary characteristics.

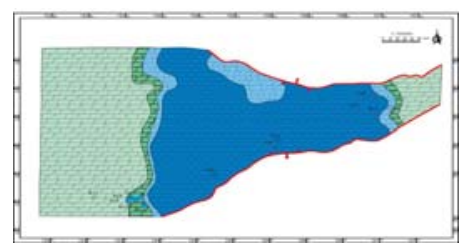

Figure 4. Sedimentary facies of early Cambrian epoch in the floor plan

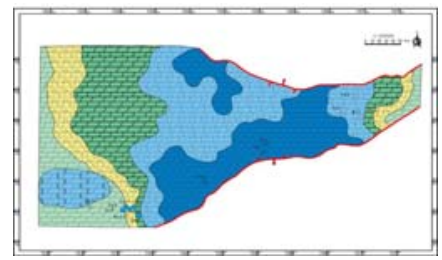

Figure 5. Sedimentary facies plot of middle Cambrian in east Tarim basin

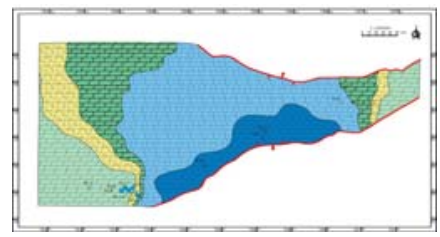

Figure 6. Sedimentary facies plot of late Cambrian in east Tarim basin

\section{V.CONCLUSION}

Seismic facies recognition technology can instruct the research of the sedimentary facies of Cambrian in East Tarim basin. The rupture is obvious at Gucheng and Luoxi tablelan, which is belong to strong hydrodynamic and boundary steep type of Wilson's (1975) three edge carbonate shelf margin mode. Series of edge shallow seismic facies vertical accretion, prograde composite characteristics of Cambrian can be identified from seismic section. Rupture controlled the favorable reservoir belt of platform-margin beach facies. above the rupture is platform facies and the favorite developing part of platform margin high-energy reef, reef - beach complex. Beneath the rupture is a deep sea basin area.

\section{REFERENCES}

[1] Shao Longyi, He Zhiping, Gu jiayu, etc., lithofacies palaeogeography of the tarim basin paleogene, Journal of Palaeogeography, 2006, 03.

[2] Shang Xiaoguang, Bao Wutang, Liu Pizhe, The geological evolution rule forecasted by using seismic facies change, China Coal Geology, 2013, 11.

[3] Chen Hongjun, Huang Wenkai, Wu Jiaoqi, Typical seismic facies, sedimentary facies characteristics of late quaternary in the northwest of south sea of China, Forefront of Marine Geology, 2013, 11.

[4] Zheng Jianfeng, Shen Anjiang, Liu Yongfu and so on, the tarim basin associated with evaporite Cambrian dolomite reservoir characteristics and main control factors. Journal of Sedimentation, 01, 2013.

[5] Zhou Xiaobei, Li Jianghai, Fu Chenjian, etc., Northern tarim basin, south China age- Cambrian tectonic background and tectonic sedimentary events, China Geology, 2012, 04.

[6] Pan Wenqing, Wang Zhaoming, Sun Chonghao, Tarim basin upper Paleozoic carbonate rock strata under sequence interface classification and its significance, Oil and Natural Gas Geology, 2011, 04. 